\title{
Hubungan Kepadatan Nerita undata dengan Tipologi Mangrove di Resort Kucur Taman Nasional Alas Purwo Banyuwangi
}

\author{
Arif Rafi Sujatmiko, Rosyid Ridho, Fuad Ardiansyah \\ Program Studi Biologi, Fakultas Matematika dan Ilmu Pengetahuan Alam \\ Universitas PGRI Banyuwangi \\ Email: fuad.bio87@gmail.com
}

\begin{abstract}
ABSTRAK
Gastropoda Nerita undata merupakan salah satu spesies yang memiliki ingsang dan operculum dari famili neritidea, gastropoda ini merupakan gastropoda umum yang ditemukan di vegetasi hutan mangrove Resort Kucur Taman Nasional Alas Purwo, gastropoda ini hidup berkelompok dengan membebentuk koloni sebagai komunitas yang mendiami hutan mangrove dengan populasi yang beragam dan berada dalam jumlah besaran dan kondisi yang berbeda pula. Mangrove dapat mengakumulasikan material organik yang terbawa oleh aliran air, sehingga terjadi adanya sedimentasi yang kemudian oleh gastropoda untuk tempat mencari makan, dan habitat tempat tinggal. Tujuan penelitian ini untuk: (1) Untuk mengetahui kepadatan Nerita undata pada hutan mangrove Resort Kucur Taman Nasional Alas Purwo; (2)Untuk mengetahui indeks nilai penting hutan mangrove di Resort Kucur Taman Nasional Alas Purwo; (3)Untuk mengetahui keterkaitan kerapatan mangrove dengan kepadatan Nerita undata pada hutan mangrove Resort Kucur Taman Nasional Alas Purwo.Metode yang digunakan dalam pengambilan data vegetasi mangrove yaitu dengan metode transek plot, pada tiap transek masing-masing dibuat plot dengan ukuran $20 \mathrm{~m} \times 20 \mathrm{~m}$ untuk pohon, kemudian didalam plot tersebut dibuat plot yag lebih kecil berukuran $10 \mathrm{~m} \times 10 \mathrm{~m}$ untuk tregakan pancang, dan didalam plot ini dibuat lagi plot berukuran $5 \mathrm{~m} \times 5 \mathrm{~m}$ untuk ukuran tiang. Hubungan kepadatan Nerita undata di vegetasi hutan mangrove resort kucur taman nasional alas purwo menununjukan bahwa hubungan antara kerapatan vegetasi mangrove dengan kepadatan Nerita undata menunjukan dengan nilai $\mathrm{R}^{2}=1$. Hal ini menujnukan bahwa kenaikan kerapatan jenis mangrove diikuti oleh tingginya kepadatan Nerita undata sehingga kerapatan vegetasi mangrove seperti jenis mangrove Rhizophora mucronata, Rhizophora apiculata juga berpengaruh terhadap keberadaanya.

Kata kunci : kepadatan, Nerita undata, Mangrove, Tipologi
\end{abstract}

\section{ABSTRACT}

Gastropoda Nerita undata is one of the species that has the ingsang and operculum of the family of neritidea, this gastropod is a common gastropod found in mangrove 
forest vegetation Resort Kucur Alas Purwo National Park, this gastropod live in groups with making colony as a community that inhabit mangrove forest with a population of varied and are in different quantities and conditions. Mangroves can accumulate organic material carried by the water flow, resulting in sedimentation by gastropods for feeding, and habitat of dwelling. The purpose of this research is to: (1) To know the density of Nerita undata in mangrove forest of Resort Kucur Alas Purwo National Park; (2) To find out the important value index of mangrove forest at Resort Kucur Alas Purwo National Park; (3) To know the relation of mangrove density with density of Nerita undata in mangrove forest Resort Kucur National Park Alas Purwo. Metode used in data collection of mangrove vegetation that is by transect plot method, in each transect each made plot with size $20 \mathrm{~m} \times 20 \mathrm{~m}$ for tree, then inside the plot is made a smaller plot with size $10 \mathrm{~m} \times 10 \mathrm{~m}$ for pancang stake, and in this plot is made again plot size $5 \mathrm{~m} \times 5 \mathrm{~m}$ for the size of poles. Related density Nerita undata in the mangrove forest vegetation resort kucur of national park alas purwo pads show that the relationship between the density of mangrove vegetation and the density of Nerita undata shows with the value of $\mathrm{R}^{2}=0,7901$. This suggests that the increase in mangrove density is followed by high Nerita undata density so that the density of mangrove vegetation such as mangrove Rhizophora mucronata, Rhizophora apiculata also affect its existence.

Keywords: density, Nerita undata, Mangrove, Typology

\section{PENDAHULUAN}

Wilayah pesisir merupakan wilayah peralihan antara daratan dan lautan yang memiliki beragam ekosistem, salah satunya adalah ekosistem mangrove (Onrizal, 2008). Dari segi ekologis kawasan hutan mangrove memiliki fungsi yang cukup kompleks diantaranya sebagai sumber bahan organik, sebagai daerah asuhan, tempat mencari makan, dan daerah pemijahan dari berbagai jenis biota laut dan pesisir (Utina, et al., 2013). Hutan mangrove sendiri memiliki vegetasi penyusun yang unik, yang berbeda pada lingkungan mangrove yang lain, pada beberapa hutan mangrove memiliki komponen abiotik serta letak yang berbeda, sehingga dari kondisi tersebut mengakibatkan terbentuknya zonasi dari pertumbuhan dan persebaran mangrove, hal ini terkait dari kemampuan dan adaptasi mangrove yang pada setiap jenis memiliki kemampuan yang berbeda.

Habitat sebagian fauna laut yang mendiami pada zonasi mangrove, memiliki keragam jenis maupun spesies biota baik berasal dari daratan maupun dari lautan, serta fauna khas penghuni kawasan mangrove seperti dari jenis crustacea, 
echinodermata, ikan, bivalvia, dan gastropoda (Ghufran, 2012). Gastropoda merupakan salah satu fauna penghuni pada kawasan mangrove, yang dapat dikategorikan dalam kelompok pendatang dan penghuni asli. Kelompok pendatang adalah fauna yang berada di kawasan mangrove hanya sebagian saja dari siklus hidupnya, sedangkan penghuni asli menghabiskan seluruh siklus hidupnya pada kawasan mangrove. Salah satu sepesies gastropoda penghuni asli yang terdapat di kawasan mangrove dari kelompok Neritidae adalah Nerita undata, Keberadaan Nerita undata pada hutan mangrove dipengaruhi oleh kondisi lingkungan, seperti tingkat kerapatan mangrove dan jenis dominasi mangrove yang berada dalam suatu ekosistem.

Banyaknya jumlah gastropoda Nerita undata yang menempati ekosistem mangrove berperan penting dalam proses rantai makanan, karena dapat mendukung kehidupan hewan lain yang lebih tinggi tingkat trofiknya, selain itu Nerita undata juga merupakan hewan dekomposer yang memakan sisa-sisa bahan-bahan organik yang terdapat pada hutan mangrove. Pada beberapa penelitian, seperti struktur komunitas gastropoda pada ekosistem mangrove (Hartoni, 2012), komposisi dan kelimpahan moluska, (Rafki, 2010), keaneka ragaman dan pola distribusi gastropoda mangrove (Lina, 2016), Nerita undata memiliki jumlah kepadatan yang dominan dari beberapa area hutan mangrove. Sehingga kehadiran gastropoda Nerita undata di hutan magrove dimungkinkan dapat memberikan suatu hubungan timbal balik yang positif terhadap ekosistem mangrove, dan dapat hidup optimal pada keadaan ekosistem mangrove yang seimbang.

Hutan mangrove pada Resort Kucur yang masuk wilayah Taman Nasional Alas Purwo dan tergolong hutan mangrove yang masih alami, hal ini terlihat dari komponen-komponen botik dan abiotik di lingkungan tersebut yang masih dalam keadaan seimbang, seperti kemampuan ekosistem yang keberadanya dapat bertahan lama, atau kesinambunganya dapat terpelihara, sehingga dimungkinkan banyak ditemukan gastropoda dari jenis Nerita undata yang bisa ditemui pada kawasan 
hutan mangrove utamanya pada Resort Kucur. Hal ini tentunya dapat menjadkani suatu acauan akan kepadatan dari keberadaan Nerita dengan vegetasi mangrove.

Pada vegetasi hutan mangrove memiliki formasi susunan jenis mangrove dan kerapatan yang berbeda pada setiap wilayah. Hal ini menjadi salah satu faktor penting untuk dilakukanya penelitian apakah kerapatan dan jenis mangrove dapat mempengaruhi terhadap kepadatan Nerita undata di Resort Kucur Taman Nasional Alas Purwo.

\section{METODE PENELITIAN}

\subsection{Waktu dan Tempat}

Penelitian dilaksanakan pada Mei-Juni 2017 di ekosistem mangrove Kawasan Resort Kucur Taman Nasional Alas Purwo. Identifikasi jenis spesies maupun analisis hasil penelitian dilakukan di laboratorium Biologi Fakultas Matematika dan Ilmu Pengetahuan Alam Universitas PGRI Banyuwangi.

\subsection{Prosedur Penelitian}

Penelitian dilakukan di vegetasi hutan mangrove Resort Kucur Taman Nasional Alas Purwo seluas 16 hektar yang mana dalam penentuan lokasi sebesar 2-4\% dari total luas wilayah, Dari perhitungan luas wilayah tersebut didapatkan 3 stasiun penelitian yang mana pada satu stasiun memiliki luas $10.000 \mathrm{~m}^{2}$.

penentuan transek dan plot gastropoda dengan cara penetapan dari arah laut ke darat (tegak lurus garis pantai sepanjang zonasi hutan mangrove), pada setiap stasiun yang sudah ditetapkan dibuat 4 transek dan 40 plot dengan ukuran plot yang telah ditentukan seluas $2 \mathrm{~m} \times 2 \mathrm{~m}$ sedangakn jarak antar plot sejauh $10 \mathrm{~m}$, dan jarak antar transek 30m sebagaimana gambar berikut 


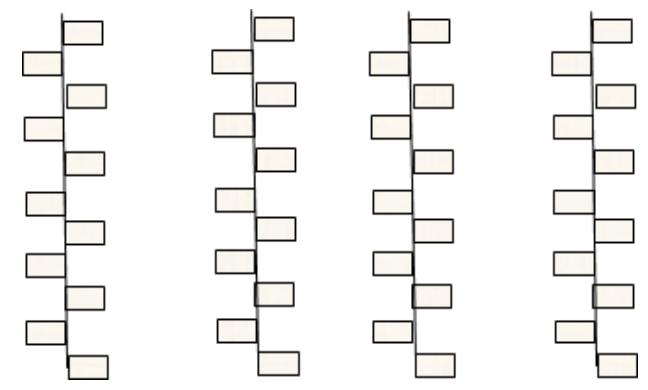

\section{Gambar 2. Transek dan plot pengambilan data gastropoda}

Metode yang digunakan dalam penelitian yaitu dengan mengunakan transek plot, yaitu tehnik pengambilan sampel dimana semua individu dalam populasi baik secara sendiri-sendiri atau bersama-sama diberi kesempatan yang sama untuk dipilih sebagai anggota sampel, dimana lokasi penelitian terdiri dari 3 stasiun. Penentuan transek pada setiap stasiun sejumlah 2 transek yang terdiri dari 4 plot mangrove yang masing-masing terdiri dari plot tiang berukuran $5 \mathrm{~m} \times 5 \mathrm{~m}$, plot panacang $10 \mathrm{~m} \times 10 \mathrm{~m}$, dan plot pohon $20 \mathrm{~m} \times 20 \mathrm{~m}$. Lokasi dan sketsa plot pengambilan sampel mangrove adalah seperti contoh gambar berikut;

\begin{tabular}{|c|}
\hline \multicolumn{2}{|c|}{ Pohon $20 \mathrm{~m} \times 20 \mathrm{~m}$} \\
\hline Pancang $10 \mathrm{~m} \times 10 \mathrm{~m}$ \\
\hline Tiang \\
$5 \mathrm{~m} \times 5 \mathrm{~m}$ \\
\\
\end{tabular}

\section{Gambar 3. Plot pengambilan data mangrove}

\subsection{Analisis Data}

a) Untuk menghitung kepadatan individu gastropoda Nerita undata dilakukan dengan mengunakan rumus berikut (Brower et al., 1989);

$$
\left.\mathrm{Di}=\frac{N i}{A} \text { individu } / \mathrm{m}\right)
$$

Keterangan : $\quad D_{i}=$ jumlah individu (tegakan) ke-i per satuan luas

$$
\mathrm{Ni}=\text { jumlah individu (tegakan) ke-i dalam transek kuadrat }
$$




$$
\mathrm{A}=\text { luas transek kuadrat }
$$

b) Untuk mengetahui tipologi mangrove, data yang perlu diketahui adalah:

$$
\begin{aligned}
& \checkmark \text { Kerapatan }=\frac{\text { Jumlah individu suatu jenis (N) }}{\text { Luas petak contoh (ha) }} \\
& \checkmark \text { Kerapatan Relatif (KR) }=\frac{\text { Kerapatan suatu jenis (K) }}{\text { Kerapatan seluruh jenis }} \times 100 \% \\
& \checkmark \text { Frekuensi (F) }=\frac{\text { Jumlah plotditemukan suatu jenis }}{\text { Jumlah seluruh plot }} \\
& \checkmark \text { Frekuensi Relatif (FR) }=\frac{\text { Frekuensi suatu jenis (F) }}{\text { Frekuensi seluruh jenis }} \times 100 \% \\
& \checkmark \text { Dominansi (D) }=\frac{\text { Jumlah Bidang Dasar suatu jenis }}{\text { Luas petak contoh (ha) }} \\
& \checkmark \text { Dominansi Relatif (DR) }=\frac{\text { Dominansi suatu jenis (D) }}{\text { Dominansi seluruh jenis }} \times 100 \%
\end{aligned}
$$

Data yang diperoleh digunakan untuk menghitung kerapatan, frekuensi jenis, dominasi dan indeks nilai penting ( the important value) menurut Bengen (2004), nilai penting jenis di dapatkan dengan mengunakan persamaan sebagai berikut:

$$
\mathrm{INP}=\mathrm{KRi}+\mathrm{FRi}+\mathrm{DRi}
$$

Nilai penting ini memberikan suatu gambaran mengenai pengaruh atau peranan suatu jenis tumbuhan mangrove dalam komunitas. Indeks nilai penting merupakan penjumlahan dari nilai kerapatan relatif $n$ jenis-i $\left(D_{i}\right)$, frekuensi relatif jenis $\left(\mathrm{FR}_{\mathrm{i}}\right)$ dan dominasi relatif jenis-i $\left(\mathrm{DR}_{\mathrm{i}}\right)$

c) Hubungan antara kepadatan Nerita undata dengan tipologi mengrove dapat di jelaskan dengan mengunakan analisis Regresi. Tujuan analisis ini adalah untuk mengetahui hubungan antara kedua peubah dalam hal ini hubungan antara kepadatan Nerita undata sebagai variabel tak bebas (Y) dengan kerapatan dan penutupan mengrove sebagai variabel bebas (X). Nilai korelasi (R) menjelaskan sebarapa besar hubungan antara peubah X dan Y. Semakin besar hubungan antara peubah, nilai korelasi (R) mendekati 1 (satu). Nilai koefisien determinasi $\left(\mathrm{R}^{2}\right)$ mengambarkan seberapa besar X (kerapatan mangrove) menpengaruhi Y (kepadatan Nerita undata), nilai $\mathrm{R}^{2}$ dapat di bandingkan untuk menguji ketepatan fungsi yang digunakan serta dapat meihat nilai errornya. Semakin besar nilai $\mathrm{R}^{2}$ maka semakin kecil nilai 
errornya variabel tak bebas (Y). Persamaan regresi yang digunakan berdasarkan Stell dan Torri (1960).

$$
Y=\beta_{0}+\beta_{1} x+\beta_{2} x^{2}+\ldots+\beta_{n} x^{n}
$$

Dimana:

$$
\begin{aligned}
& Y=\text { Kepadatan nerita undata } \\
& X=\text { kepadatan mangrove (pohon) } \\
& \beta=\text { ordo }(1,2,3 \ldots \text { n) }
\end{aligned}
$$

\section{HASIL DAN PEMBAHASAN}

\subsection{Kepadatan Nerita Undata}

Berdasarkan hasil penelitian gastropoda Nerita undata di Resort Kucur Taman Nasional Alas Purwo ditemukan pada setiap daerah penelitian dengan jumlah kepadatan rata-rata sebagai berikut;

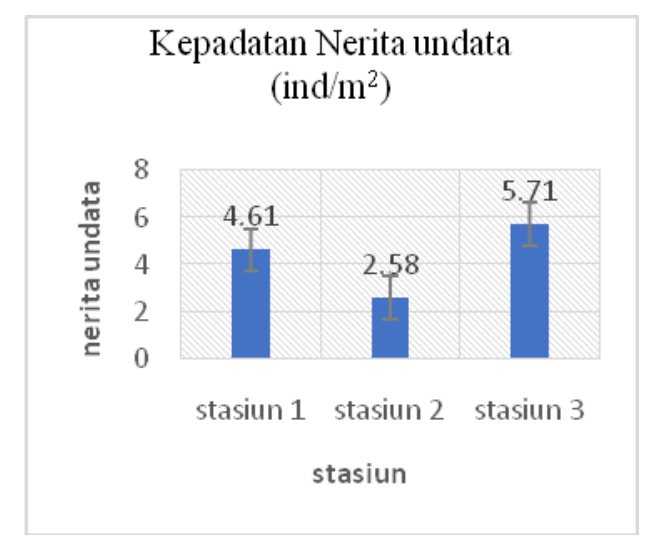

\section{Gambar 4. Kepadatan nerita undata tiap stasiun penelitian}

Pada gambar 4. dapat diketahui bahwa kepadatan Nerita undata di Resort Kucur Taman Nasional Alas Purwo menunjukan hasil yang berbeda pada setiap stasiun penelitian, kepadatan tertinggi terdapat pada stasiun 3 hal ini dapat dikarenakan stasiun 3 memiliki kerapatan dan ketinggian mangrove yang paling tinggi, yang dapat mempengaruhi dimana ketinggian pohon yang relatif pendek dapat menyediakan mikrohabitat yang lebih besar, sehingga dari semua bagian pohon bisa menjadi 
tempat melekat baik akar, batang, dan bagian pohon lainya. Pada stasiun 2 kepadatan Nerita undata memiliki nilai yang paling rendah, disebabkan oleh rendahnya nilai kerapatan vegetasi mangrove yang terdapat pada stasiun 2. Menurut Budiman (1991) menyatakan, lokasi stasiun-stasiun pengamatan dengan nilai kepadatan yang rendah, lebih disebabkan oleh kerapatan dan kekayaan jenis yang rendah, maka kondisi lingkungan pada stasiun tersebut dianggap sebagai penyebab rendahnya suatu jenis

\section{Indeks Nilai Penting (INP)}

Dari tiga lokasi stasiun penelitian tersebut, memiliki indeks niai penting (INP) yang bervariasi dengan pada tiap jenis mangrove (tabel 1).

\section{Tabel 1. Ideks nilai penting (INP)}

\begin{tabular}{|c|c|c|c|c|c|}
\hline No & Nama & $\mathrm{Kr}$ & $\mathrm{Fr}$ & Dr & INP \\
\hline 1 & Rapiculata & $20,7 \mathrm{~B}$ & 16,01 & 20,69 & 57,48 \\
\hline 2 & $R$ macronaty & 34,16 & 32,03 & 34,97 & 101,16 \\
\hline 3 & S.aiba & 29,75 & 32,03 & 28,41 & 90,19 \\
\hline 4 & $\begin{array}{c}\text { Ceriops } \\
\text { toga' }\end{array}$ & 13,05 & 16,01 & 13,42 & 42,48 \\
\hline 5 & $\begin{array}{c}\text { Avirenvia } \\
\text { matiog }\end{array}$ & 2,26 & 3,92 & 2,49 & 8,67 \\
\hline & OTAL & $100 \%$ & $100 \%$ & $100 \%$ & \\
\hline
\end{tabular}

Berdasarkan tabel 1. Pada perhitungan INP didapatkan jenis Rhizophora mucronata yang memiliki indeks nilai penting (INP) tertinggi untuk semua kategori di semua jenis mangrove yang berada di lokasi penelitian. Besarnya nilai INP menunjukkan adanya pengaruh lingkungan tempat tumbuh, seperti kelembapan, suhu serta ketidakmampuan suatu spesies dalam berkompetisi, seperti perebutan zat hara, sinar matahari, dan ruang tumbuh dengan jenis-jenis lainya yang sangat mempengaruhi prtumbuhan suatu spesies. Menurut Odum (1971), jenis yang dominan memiliki produktivitas yang besar, dan dalam suatu jenis vegetasi dominan, yang perlu diketahui adalah diameter batangnya. Keberadaan jenis dominan pada setiap stasiun menjadi suatu indikator bahwa komunitas tersebut berada pada habitat yang sesuai dan mendukung pertumbuhanya. Nilai INP jenis Rhizophora mucronata berkisar 101,16, hal ini berarti bahwa jenis mangrove ini berperan penting dalam 
ekosistem, Aksornkoae (1993), mengatakan bahwa ekosistem mangrove yang digenangi air laut hampir setiap saat, hanya jenis Rhizophora sp yang bisa bertahan, sedangkan jenis lain seperti Bruguiera sp dan Xylocarpus sp jarang menempati suatu daerah yang tergenang.

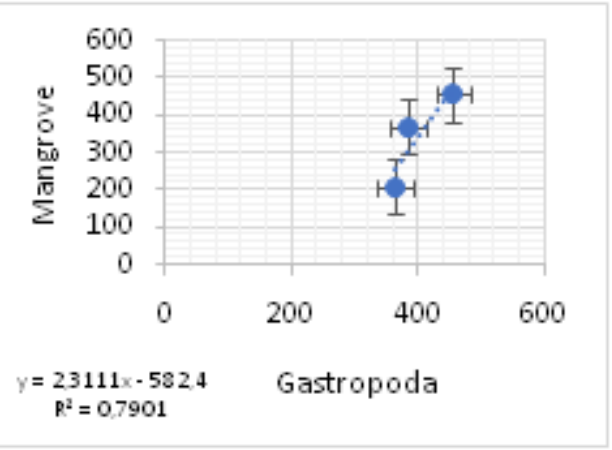

\section{Gambar 5. Hubungan kepadatan nerita undata dengan kerapatan mangrove.}

Hubungan antara kerapatan mangrove dan kepadatan Nerita undata dapat dijelaskan dengan persamaan $\mathrm{Y}=2,3111 \mathrm{x}$ - 582,4 (gambar 4.7). Koefisien determinasi $\left(\mathrm{R}^{2}\right)$ memberi suatu ukuran tentang persamaan yang diperkirakan, selain itu $\mathrm{R}^{2}$ merupakan ukuran untuk mengetahui kualitas model regresi, jadi besar kecilnya nilai koefisien determinasi menyatakan tinggi rendahnya kualitas regresi. Jadi semakin mendekati 1 artinya variabel bebas (X) semakin baik untuk meramalkan variabel tak bebas (Y).

Berdasarkan gambar 5. menununjukan bahwa hubungan antara kerapatan vegetasi mangrove dengan kepadatan nerita undata menunjukan dengan nilai $\mathrm{R}^{2}=$ 0,7901. Hal ini menujnukan bahwa kenaikan kerapatan jenis mangrove diikuti oleh tingginya kepadatan Nerita undata. Kerapatan vegetasi mangrove seperti jenis mangrove Rhizophora mucronata, Rhizophora apiculata berpengaruh terhadap keberadaan gastropoda Nerita undata. Mangrove jeis ini merupakan mangrove sejati yang umum banyak terdapat di vegetasi hutan mangrove (pribadi, 2009). Berdasarkan hal tersebut, maka kerapatan jenis vegetasi mangrove yang terdapat di hutan mangrove Resort Kucur Taman Nasional Alas Purwo mengindikasikan jumlah dari nilai kepadatan gastropoda Nerita undata, karena kerapatan jenis vegetasi yang Inventarisasi serangan hama kutu putih (mealybug) pada tanaman singkong di kecamatan rogojampi dan |33 singojuruh 
tertinggi di lokasi pengamatan adalah dari jenis mangrove Rhizophora mucronata, yang lebih banyak ditemukan dari seluruh plot pengamatan degan tingkat kerapatan jenis terpadat dan kerapatan yang tinggi.

Menurut Dewiyanti (2004), jenis magrove Rhizophora mucronata merupakan jenis mangrove pioner sehingga berpengaruh terhadap gastropoda didalamnya, karena gastropoda dapat menempel pada akar-akar mangrove saat air pasang terutama jenis gastropoda Nerita undata. Dilokasi pengamatan vegetasi hutan mangrove Resort Kucur Taman Nasional Alas Purwo, gastropoda jenis Nerita undata merupakan jenis gastropoda yang paling banyak di jumpai di bagian akar, batang dan dahan dari mangrove. Maka dari pernyataan tersebut, kerapatan jenis vegetasi mangrove yang padat dan rapat mampu mempengaruhi kepadatan gastropoda nerita undata.

\section{KESIMPULAN DAN SARAN}

\subsection{Kesimpulan}

Berdasarkan hasil yang diperoleh maka didapatkan kesimpulan sebagai berikut:

1. Kepadatan gastropoda Nerita undata, tertinggi terdapat pada stasiun 3 dengan kepadatan rata-rata $(5,71 \mathrm{ind} / \mathrm{m} 2)$. Kepadatan Nerita undata tertinggi pada ekosistem mangrove bagian belakang yang berhadapan langsung dengan perairan. Nerita undata ditemukan pada bagian batang dan pada akar mangrove

2. Pada perhitungan INP didapatkan jenis Rhizophora mucronata yang memiliki Indeks nilai penting (INP) tertinggi untuk semua kategori di semua jenis mangrove dengan nilai INP 101,16. Keberadaan jenis Rhizophora mucronata yang dominan dilokasi penelitian menandakan bahwa jenis tumbuh dan berkembang dengan baik dan mampu beradaptasi terhadap kondisi lingkungan.

3. Tingkat kepadatan gastropoda Nerita undata terhadap kerapatan mangrove memiliki keterkaitan yang cukup tinggi, hal ini ditunjukkan dengan adanya hubungan yang erat antara kerapatan mangrove dengan kepadatan Nerita undata dengan koofisien korelasi $\mathrm{R}=0$,7901. Hal ini menujnukan bahwa kenaikan kerapatan mangrove diikuti oleh tingginya kepadatan Nerita undata. 


\subsection{Saran}

Pada penelitian ini dilakukan pada lokasi dengan struktur komunitas mangrove yang berada paling depan dan relatif homogen. Untuk selanjutnya disarankan memilih lokasi yang berada di area yang memiliki struktur komunitas yang lebih banyak. mangrove yang lebih heterogen atau pada komunitas mangrove yang didominasi oleh jenis mangrove lainnya, dengan demikian diharapkan akan diketahui keterkaitan lebih jauh antara gastropoda dengan struktur mangrove yang berbeda.

\section{REFERENSI}

Aksornkoae S. 1993. Ecology and Management of Mangroves. Bangkok: IUCN Bengen DG. 2004. Pedoman Teknis Pengenalan dan Pengelolahan Ekosistem Mangrove . Bogor: Pusat Kajian Sumber Daya Pesisir dan Lautan, Institut Pertanian Bogor.

Brower, J.E. and J.H. Zar. 1989. Field and laboratory methods for general ecology. W.C. brown publisher.USA.

Budiman A. 1991. Penelaahan Beberapa Gatra Ekologi Moluska Bakau Indonesia (disertasi). Jakarta: Program Pascasarjana, Universitas Indonesia.

Dewiyanti, i. 2004. Struktur komunitas moluska serta asosiasinya pada ekosistem mangrove di kawasan pantai ulhe-lhe banda aceh. Skripsi. Bogor: institut pertanian bogor.

Ghufran, H. Kordi. M. 2012. Ekosistem Mangrove: Potensi, Fungsi, dan Pengelolahan. Jakarta: Rineka Cipta.

Hartoni, dkk. 2012. Komposisi dan kelimpahan moluska di ekosistem mangrove muara sungai musi Kabupaten Banyuasin Provinsi Sumatera selatan. Jurnal ilmu kelautan.sumatra selatan: universitas sriwijaya.

lina, 2016. Keanekaragaman dan Pola Distribusi Gastropoda Mangrove di Teluk Pangpang Blok Jati Papak Taman Nasional Alas Purwo Banyuwangi. Skripsi. Banyuwangi: Pascasarjana Program Studi Pendidikan Biologi Universitas PGRI Banyuwangi. universitas PGRI Banyuwangi.

Odum, E. P. 1971. Fundamentals Of Ecology. W. B. Sounders company Ltd.philadelphia

Onrizal, 2008. Tehnik Survei dan Analisa Data Sumber Daya Mangrove. Makalah. Pelatihan dan Pengolahan Hutan Mangrove Departemen Kehutanan Fakultas Pertanian Universitas Sumatera Utara

Pribadi. 2009. Komposisi jenis dan distribusi gastropoda di kawasan hutan mangrove segara anakan cilacap. Jurnal ilmu kelautan. Semarang: universitas diponegoro.

Rafki, dkk. 2010. Struktur komunitas gastropoga pada ekosistem mangrove di muara sungaibatang ogan komering ilir sumatera selatan. Jurnal ilmu kelautan.sumatra selatan: universitas sriwijaya.

Steel RGD dan torrie JH. 1960. Principle And Procedures Of Statistic With Special 
Reference To The Biological Sciences. New york: mcGraw-Hill Book Company, Inc.

Sudarmadji. 1995. Analisis Vegetasi di Hutan Mangrove di Hutan Hijau Sepanjang Tahun Taman Nasional Baluran. Departemen Pendidikan dan Kebudayaan Republik Indonesia . Jember: Universitas Jember.

Utina, R., dkk. 2013. Deskrip Siperbedaan Jumlah Individu Kepiting Bakau Scylla serrata dan Uc sp. Serta Hubunganya Dengan Faktor Lingkungan Pada Ekosistem Mangrove di Desa Bulalo Kecamatan Kwandang Kabupaten Gorontalo Utara. Tesis. Gorontalo: Pascasarjana Program Studi Pendidikan Biologi Universitas Negri Gorontalo. 